\title{
Determination of Susceptibility to Intergranular Corrosion of UNS 31803 Type Duplex Stainless Steel by Electrochemical Reactivation Method
}

\author{
Mehmet Emin Arıkan, ${ }^{1}$ Rafet Arıkan, ${ }^{2}$ and Mustafa Doruk ${ }^{1}$ \\ ${ }^{1}$ Department of Metallurgical \& Materials Engineering, METU, 06531 Ankara, Turkey \\ ${ }^{2}$ Department of Mechanical Engineering, Atılım University, Incek, 06836 Ankara, Turkey
}

Correspondence should be addressed to Rafet Arıkan, rarikan@atilim.edu.tr

Received 25 September 2011; Revised 10 December 2011; Accepted 19 December 2011

Academic Editor: Rokuro Nishimura

Copyright () 2012 Mehmet Emin Arıkan et al. This is an open access article distributed under the Creative Commons Attribution License, which permits unrestricted use, distribution, and reproduction in any medium, provided the original work is properly cited.

\begin{abstract}
Specimens taken from a hot-rolled cylindrical duplex stainless steel (DSS) bar with $22 \%$ Cr grade were solution annealed at $1050^{\circ} \mathrm{C}$ and then aged at $725^{\circ} \mathrm{C}$ from 100 to $31622 \mathrm{~min}$ for sensitization treatment. Double loop electrochemical potentiodynamic reactivation and standard weight loss immersion acid tests were conducted. The solution-annealed samples were found unsensitized. Those samples aged for 100 and $316 \mathrm{~min}$ were less sensitized whereas samples aged for 1000 min and especially those aged for 3162,10000 , and 31622 min were heavily sensitized. The degree of sensitization (DOS) can be attributed to higher contribution of chromium- and molybdenum-depleted areas resulting from intermetallic phases.
\end{abstract}

\section{Introduction}

Generally, duplex stainless steels (DSS) are Fe-Cr-Ni alloys having an approximately volumetric fraction of $50 \%$ ferrite and $50 \%$ austenite in their microstructures. Their main feature is that they compromise the favorable corrosion resistance of austenitic stainless steels with good mechanical properties [1-4].

In duplex stainless steels undesirable phases such as intermetallic phases (sigma and chi), carbides, and nitrides may exist if the manufacturing processes are not carefully controlled. High levels of elements stabilizing ferrite, such as chromium, molybdenum, and silicon, can promote the formation of sigma phase $(\sigma)$. Sigma phase $(\sigma)$ is a hard and brittle intermetallic phase, which is generally formed between 600 and $950^{\circ} \mathrm{C}$ with rapid formation kinetics [5-7]. Additional phases found in duplex stainless steels can include chi $(\chi)$, laves $(\eta)$, and $\alpha^{\prime}$ [8]. The nucleation sites for $\sigma$ and $\chi$ phases are grain boundaries, incoherent twin boundaries, and dislocations. Duplex stainless steels are susceptible to sensitization due to the precipitation of additional phases when heated in a temperature range of $600-950^{\circ} \mathrm{C}$. These phases have a reverse effect on the corrosion and mechanical properties [6, 7]. A substantial depletion of $\mathrm{Cr}$ and Mo due to a copious precipitation of $\sigma$ and $\chi$ phases results in a decrease of the corrosion properties [9].

There are several test methods for determining the sensitization to intergranular corrosion. Weight loss acid test was first standardized, and the test procedure was presented in ASTM A262-91 [10]. Corrosion rate is determined by measuring the weight loss of the sample. Another test method of measuring the degree of sensitization to intergranular corrosion involves electrochemical reactivation of the steel samples as defined in ASTM G108-94 [11]. This reactivation process is named as electrochemical potentiodynamic reactivation (EPR) and has been developed in single-loop (SLEPR) or in double-loop (DLEPR) types. The latter was first used for austenitic stainless steels. The best advantage of this technique is that it obtains a quantitative value of the degree of sensitization instead of an only qualitative appreciation as metallographic etchings. The EPR test provides the degree of sensitization of the material which is proportional to the amount of chromium-depleted areas adjacent to the Cr-rich phases. 
In this study, DLEPR was applied for the determination of susceptibility to sensitization of duplex stainless steel type UNS S31803 with 22\% Cr grade. It is designated by $\mathrm{X} 2 \mathrm{CrNiMo} 22-5-3$ with the trade name SAF2205. The summary of technical literature related to austenitic-ferritic duplex stainless steels shows that the test solution for DLEPR often consists of sulphric acid $\left(\mathrm{H}_{2} \mathrm{SO}_{4}\right)$ solution with the addition of KSCN as depassivator.

The purpose of the present work was to investigate intergranular corrosion behavior of DSS in relation to the influence of the microstructure produced by different heat treatments. This is performed by solution annealing and ageing for different times up to 22 days in order to provide different microstructure and sensitization levels. Electrochemical measurements were used to determine the degree of sensitization (DOS) to intergranular corrosion. Light optical microscopy (LOM) was used to identify the different phases that form in bulk material after the heat treatments. X-ray diffraction (XRD) technique and energy dispersive system (EDS) analysis were used for microstructural evolution. Surfaces obtained after the DLEPR test and the weight loss immersion test were also observed to check the attack locations and the relationship with the chromium-depleted areas.

A similar work was performed by Arikan and Doruk [12] on the same type duplex stainless steel aged at $650^{\circ} \mathrm{C}$ for various periods of time. The results will be compared in Section 3.6.

\section{Experimental Method}

2.1. Materials and Heat Treatments. The material used in this research was a commercial type hot-rolled bar of UNS S31803 duplex stainless steel (DSS) (trade name SAF2205). The chemical composition of the steel is given in Table 1.

The specimens were cut from a wrought cylindrical bar of $100 \mathrm{~mm}$ in diameter and $200 \mathrm{~mm}$ in length. The specimens were also in a cylindrical shape of $10 \mathrm{~mm}$ in diameter and $20 \mathrm{~mm}$ in length. They were taken from the bar in an orientation parallel to the rolling direction. In order to homogenize the structure, all specimens were subjected to a solution heat treatment at $1050^{\circ} \mathrm{C}$ for 1 hour and then quenched in water, followed by ageing heat treatments at $725^{\circ} \mathrm{C}$ for various periods of time.

2.2. Metallography. After heat treatments, the surfaces of the specimens were ground from 400 to 2000 grit emery paper. For microstructure examination, the surfaces of the specimens were polished with 9 and $1 \mu \mathrm{m}$ diamond paste. For metallographic examination, they were etched in $\mathrm{NaOH}$ solution as described in ASTM A923 [13]. It colors the phases in duplex stainless steel such as austenite in white, ferrite in light brown, sigma in dark brown, and carbides in black.

2.3. Weight Loss Test. The weight loss test was done according to ASTM A923-03 Test Method C standard. The test solution was prepared by dissolving $100 \mathrm{~g}$ of reagent grade ferric
TABLE 1: Chemical composition of 2205 DSS (wt.\%).

\begin{tabular}{lccccc}
\hline $\mathrm{C}$ & $\mathrm{Cr}$ & $\mathrm{Ni}$ & $\mathrm{Mo}$ & $\mathrm{Mn}$ & $\mathrm{Fe}$ \\
\hline 0.026 & 22.04 & 4.45 & 2.69 & 1.49 & Ret. \\
\hline
\end{tabular}

chloride $\left(\mathrm{FeCl}_{3} \cdot 6 \mathrm{H}_{2} \mathrm{O}\right)$ in $900 \mathrm{~mL}$ of distilled water $(6 \%$ $\mathrm{FeCl}_{3}$ by weight). The $\mathrm{pH}$ of the solution was adjusted to approximately 1.3 by addition of $\mathrm{HCl}$ or $\mathrm{NaOH}$. The corrosion rate was evaluated as the rate of weight loss in $\mathrm{mg}$ per sq. dm per day (mdd).

2.4. X-Ray Diffraction Analysis. The chemical composition and the profile line analysis of the phases were carried out by EDS with SEM. The presence of different phases was also identified by X-ray diffraction patterns by means of Rigaku diffractometer with $\mathrm{Cu} K_{\alpha}$ radiation.

2.5. DLEPR Tests. The susceptibility of the aged DSS to intergranular corrosion was evaluated using DLEPR test according to ASTM G108 standard [11]. The test was performed according to the recommendations of Majidi and Streicher $[14,15]$. The standard solution is modified to suit duplex stainless steels and consisted of $2 \mathrm{M} \mathrm{H}_{2} \mathrm{SO}_{4}+0.5 \mathrm{M}$ $\mathrm{NaCl}+0.01 \mathrm{M} \mathrm{KSCN}$ at $30 \pm 1^{\circ} \mathrm{C}$. The test cell consisted of a 1 litre flask with necks for electrodes. A cylindrical working electrode was centrally located, and two counter electrodes were placed next to specimen to improve the current distribution. The specimen was mounted according to Stern-Makrides arrangement [11].

The potential was scanned with a rate of $15 \mathrm{~V} /$ hour in the anodic direction from a potential lower than $E_{\text {corr }}$ in the cathodic region to a point of $0.250 \mathrm{~V}$ in middle of the passive region. The scanning direction was then reversed, and hence two loops are generated. The peak activation current $\left(I_{a}\right)$ and the peak reactivation current $\left(I_{r}\right)$ were measured during the forward and backward scans, respectively. The degree of sensitization (DOS) was thus measured as the ratio of the maximum current densities, $\left(I_{r} / I_{a}\right) \times 100[14,15]$.

The activation or critical current density $\left(I_{a}\right)$ or $\left(I_{\text {crit }}\right)$ is proportional to the corrosion rate of a metal. The rate of corrosion rises rapidly in the activation range up to the activation peak current density. The potential corresponding to this is called activation peak potential $E_{a}$ or passivation potential $E_{\text {pass. }}$. If the potential is raised further, the anodic current will drop to a lower value called passivation current density $\left(I_{\text {pass }}\right)$, and then it will remain constant over a wide potential range. This is the passive range in which a thin invisible film of oxide covers the metal surface. This protective film acts as a barrier between the metal and its environment and reduces the rate of dissolution.

During the anodic sweep, the entire surface is active and contributes to the peak current. But during the reactivation sweep, only the sensitized regions contribute to the passiveactive transition. The unsensitized specimens show a small $I_{r}$ and results in a small $\left(I_{r} / I_{a}\right)$ ratio. On the other hand, in heavily sensitized specimens, $I_{r}$ approaches $I_{a}$ resulting in a high $\left(I_{r} / I_{a}\right)$ ratio. 


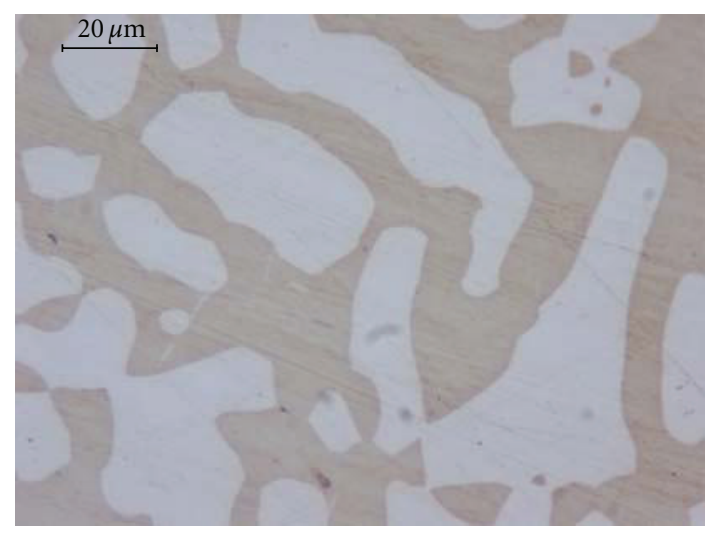

Figure 1: Microstructure of DSS, solution annealed at $1050^{\circ} \mathrm{C}$ for 1 hour (austenite in white, ferrite in gray).

\section{Results and Discussion}

3.1. Metallographic Examination. The optical micrographs obtained by etching with $\mathrm{NaOH}$ reagent are given in Figures 1 and 2. Figure 1 represents the microstructure of solutionannealed parent alloy in which white phase is austenite $(\gamma)$ and the dark phase is ferrite $(\alpha)$. The volume fractions of $\alpha$ and $\gamma$ were 0.54 and 0.46 , respectively. The microstructure does not reveal any visible precipitates of other phases.

To study the influence of the microstructure on degree of sensitization (DOS), the specimens were aged at $725^{\circ} \mathrm{C}$ for times 100, 316, 1000, 3162, 10000 and $31622 \mathrm{~min}$. The ageing heat treatments induced a marked change in the ferrite/austenite ratio caused by the transformation [16]

$$
\alpha \longrightarrow \gamma_{2}+\sigma
$$

where $\gamma_{2}$ is the so-called secondary austenite. The nucleation rate $[17,18]$ and the growth kinetics of this reaction have been studied extensively [19]. It is well known that the controlling step is the nucleation rate. The growth of sigma phase causes a decrease in chromium and molybdenum content of the neighboring ferrite which becomes unstable and transforms into new austenite. This austenite, in turn, is rich in chromium and molybdenum and has a lower content of nickel if compared with the neighboring primary austenite. These changes in chemical composition promote the formation of an additional sigma phase. The overall result is the coprecipitation of secondary austenite and sigma.

For specimens aged at $725^{\circ} \mathrm{C}$, microstructural changes are shown in Figures 2(a) and 2(f). For ageing from 100 to $316 \mathrm{~min}$, the first tiny precipitates of sigma phase appear at $\alpha / \gamma$ and $\alpha / \alpha$ boundaries. Incoherent twin boundaries and dislocations inside the ferrite matrix may also be the nucleation sites for precipitation [20]. The precipitations of $\sigma$-phase were first encountered after ageing for $316 \mathrm{~min}$ and the size and amount of $\sigma$ phase increased with ageing time. Nucleation and growth of $\sigma$-phase are thermally activated processes involving diffusion. Therefore, temperature will have a significant effect on the kinetics of the transformation. After $1000 \mathrm{~min}$, a lot of sigma precipitates have developed at $\alpha / \gamma, \alpha / \alpha$, and inside the ferrite phase as shown in Figures 2(c) and 2(f). Longer ageing treatment leads to the increase and coarsening of the $\sigma$ phase in an irregular shape.

\subsection{Phase Volume Fraction by Light Optical Microscopy.} Microanalysis reveals that the solution-annealed material consists of ferrite and austenite phases. The main microstructural change during ageing is the formation of $\sigma$-phase and secondary austenite $\left(\gamma_{2}\right)$ from the ferrite phase due to the eutectoid reaction $\left(\alpha \rightarrow \sigma+\gamma_{2}\right)$. The amounts of phases were estimated by measuring the fractions of colored area on polished and etched specimens by light optical microscopy (LOM). The measured volume fractions of ferrite, austenite, and sigma phases for different ageing times are given in Table 2 and Figure 3. Since the ferrite transforms into $\sigma$ and $\gamma_{2}$, the ferrite phase decreases as the volume percentages of sigma and secondary austenite increase with ageing time until the whole ferrite is totally consumed. Ferrite continuously decreases throughout each of the isothermal holds and reaches zero at the end of the $31622 \mathrm{~min}$. The total austenite is considered as the sum of the primary and secondary austenite $\left(\gamma+\gamma_{2}\right)$ and increases to the value of $57 \%$ by time.

During the early stages of the transformation, sigma forms preferentially at the $\alpha / \gamma$ and $\alpha / \alpha$ grain boundaries and inside the $\alpha$-grain and grows into the ferrite phase via a transformation mechanism involving diffusion. Because both nucleation and diffusional growth of $\sigma$ are thermally activated processes, the ageing time and temperature will have a significant effect on the kinetics of the transformation. The time at which sigma was first observed was $316 \mathrm{~min}$ at $725^{\circ} \mathrm{C}$.

3.3. Weight Loss Test Results. The degree of sensitization is also given by the loss of weight due to the dissolution of chromium-depleted areas and is expressed as the rate of weight loss in mdd. The results of standard weight loss immersion test are given in Table 3 and plotted in Figure 4. Corrosion rate of the specimens aged at $725^{\circ} \mathrm{C}$ is low up to $1000 \mathrm{~min}$ and then increases rapidly up to $31622 \mathrm{~min}$. Moreover, the lower chromium and molybdenum content is not the only factor responsible for the increase in the rate of corrosion. The neighborhood of more noble phases (sigma phase) will enhance the anodic dissolution of secondary austenite extensively.

The surfaces of the corroded specimens were examined using LOM. The localized attack in black points is initiated in the secondary austenite phase adjacent to the sigma phase as shown in Figure 5. The austenite and the sigma phase resist the ferric chloride solution more than the ferrite and the secondary austenite. Once a pit is formed it rapidly propagates within the initial ferrite region. As a result, it is observed that the sigma and austenite phases are almost intact, while the secondary austenite $\left(\gamma_{2}\right)$ and some iron rich ferrite phases are attacked.

3.4. EDS Analysis of Phases. The precipitation of the intermetallic sigma phase is accomplished by the formation 


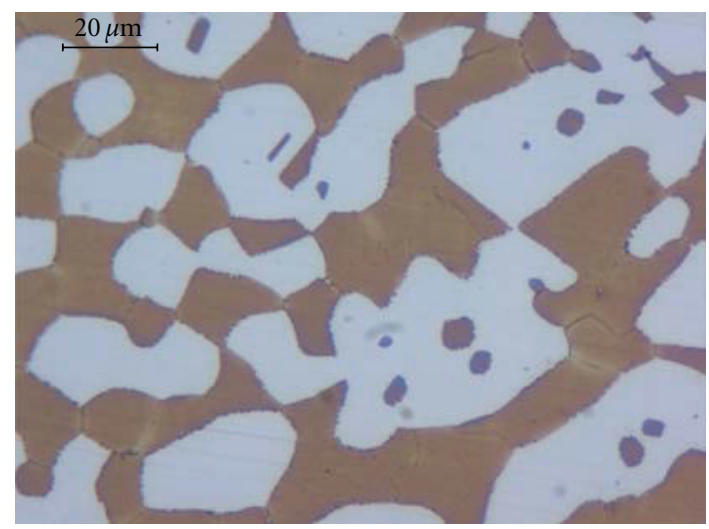

(a)

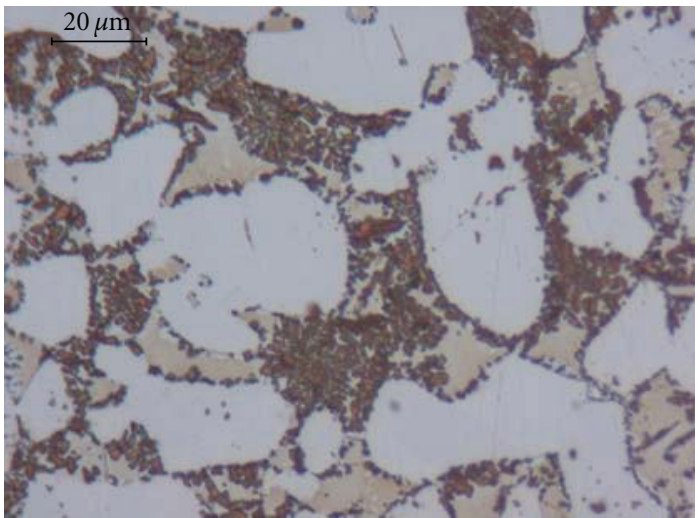

(c)

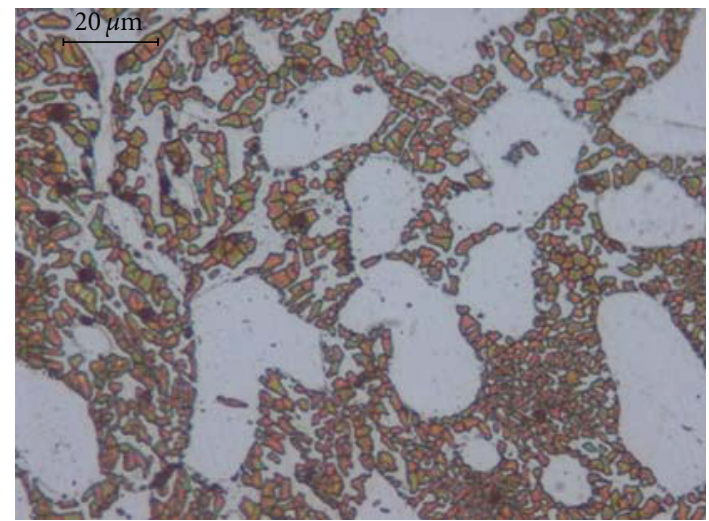

(e)

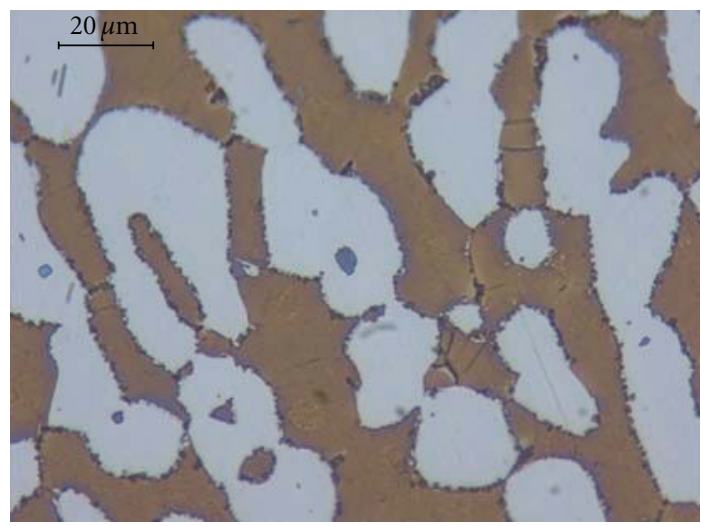

(b)

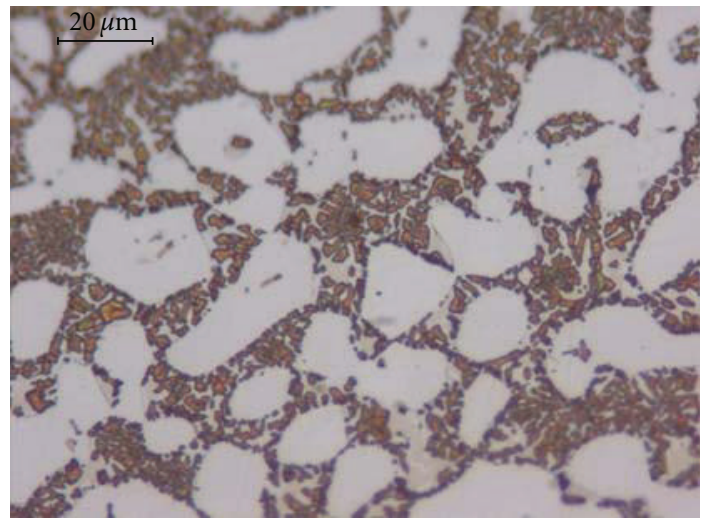

(d)

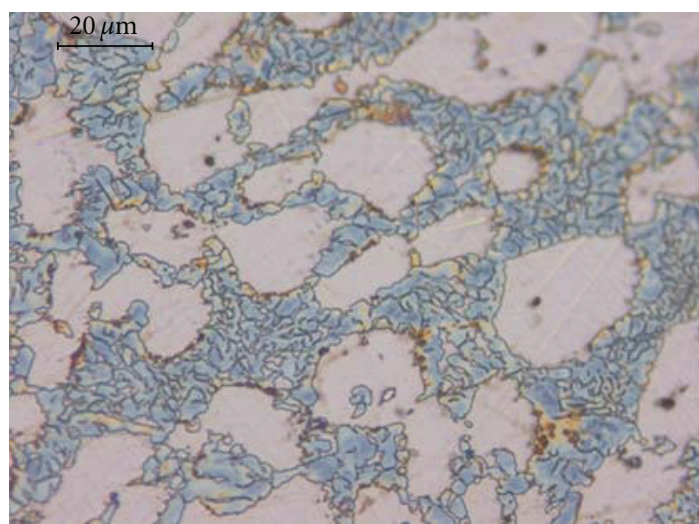

(f)

FIGURE 2: Optical micrographs obtained after ageing at $725^{\circ} \mathrm{C}$ by etching with $\mathrm{NaOH}$ reagent (a) $100 \mathrm{~min}$, (b) $316 \mathrm{~min}$, (c) $1000 \mathrm{~min}$, (d) $3162 \mathrm{~min}$, (e) $10000 \mathrm{~min}$, (f) $31622 \mathrm{~min}$ (austenite in white, ferrite in gray, sigma precipitates in black).

of secondary austenite $\left(\gamma_{2}\right)$. As the sigma phase grows, chromium and molybdenum are enriched in these precipitates, and, simultaneously, nickel diffuses into the ferrite. The enrichment of $\gamma$-stabilizing elements (such as $\mathrm{Ni}$ ) in the ferrite and the loss of ferrite stabilizing elements (such as $\mathrm{Cr}$ and $\mathrm{Mo}$ ) lead to an unstable ferrite transforming into secondary austenite depleted in chromium and molybdenum [20].
The EDS measurements of $\mathrm{Cr}, \mathrm{Mo}, \mathrm{Ni}, \mathrm{Mn}$, and Fe content of the $\alpha, \gamma, \sigma$, and $\gamma_{2}$ phases present in samples of solution annealed and aged for $31622 \mathrm{~min}$ are given in Table 4 . During the growth of sigma phase, these elements diffuse from the surrounding ferrite matrix to the sigma phase, and this causes depletion in these elements. The depletion in chromium and molybdenum leads to the transformation of the region to secondary austenite $\left(\gamma_{2}\right)$. 
TABLE 2: The phase volume percentages obtained from digital image analysis.

\begin{tabular}{lcccc}
\hline Heat treatment & Ageing time $(\mathrm{min})$ & Ferrite phase $($ vol. \%) & Austenite phase $\left(\gamma+\gamma_{2}\right)($ vol. \%) & Sigma phase $($ vol. \%) \\
\hline $\begin{array}{l}\text { Solution annealed at } \\
1050^{\circ} \mathrm{C}, 1 \mathrm{~h}\end{array}$ & & 54.55 & 45.45 & 0 \\
\hline & 100 & 54 & 46 & 0 \\
Solution annealed at & 316 & 53.2 & 46.2 & 0.6 \\
$1050^{\circ} \mathrm{C}, 1 \mathrm{hr}+$ aged at & 1000 & 32 & 59 & 32 \\
$725^{\circ} \mathrm{C}$ & 3162 & 15 & 54 & 33 \\
& 10000 & 6 & 57 & 40 \\
\hline
\end{tabular}

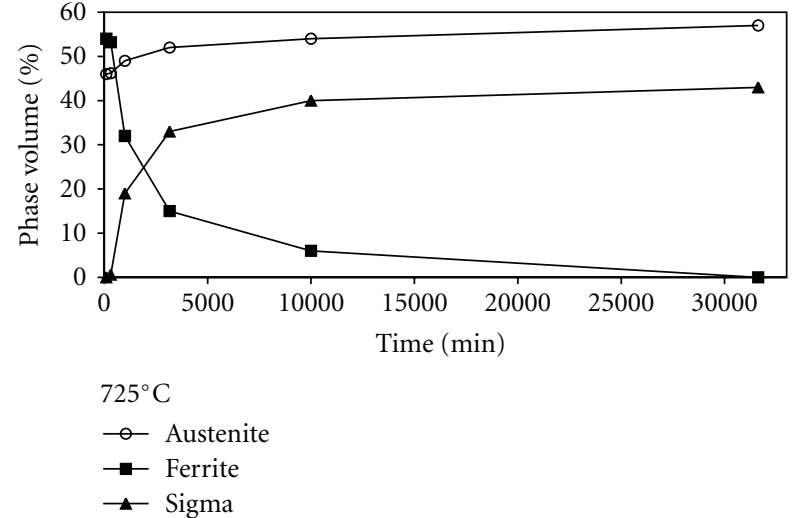

FIGURE 3: Changes in volume \% of austenite, ferrite, and sigma phases with ageing time at $725^{\circ} \mathrm{C}$.

TABLE 3: Weight loss immersion acid test results according to ASTM A 923-03.

\begin{tabular}{lc}
\hline Ageing time $(\mathrm{min})$ & Weight loss $(\mathrm{mdd})$ \\
\hline 100 & 0.49451 \\
316 & 2.37328 \\
1000 & 5.38945 \\
3162 & 5.16104 \\
10000 & 5.28002 \\
31622 & 6.04718 \\
\hline
\end{tabular}

3.5. X-Ray Diffraction Pattern. The results of the X-ray diffraction analysis consist of a series of diffraction patterns given in Figure 6. The diffraction pattern of the solutionannealed parent alloy presents ferrite and austenite phase peaks only. Samples aged at $725^{\circ} \mathrm{C}$ for different ageing times show the peaks of phases developed.

Although the precipitations at grain boundaries are evident for $316 \mathrm{~min}$ of ageing as shown in light optical micrograph of Figure 2(b), the X-ray spectra of the sample do not reveal any sigma peak. This may be attributed, as given in Table 2, to the very low volume fraction of the sigma phase $(0.6 \%)$.

Samples aged at $725^{\circ} \mathrm{C}$ show sigma peaks first in $1000 \mathrm{~min}$ of ageing. With increased holding time, the intensity of sigma peaks increases as the volume fraction of sigma phase increases (Table 2), and also additional sigma

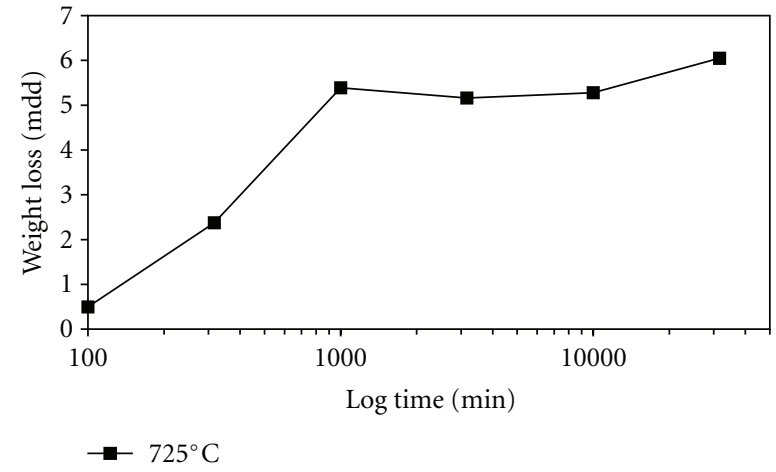

Figure 4: The change in weight loss with ageing time.

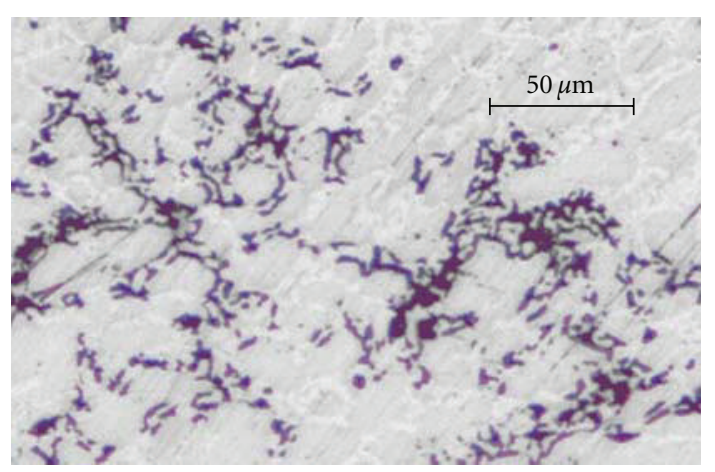

FIGURE 5: Dissolution of the secondary austenite in weight loss test (black: attacked region in the secondary austenite phase adjacent to the sigma phase, gray: austenite, and white: sigma).

peaks appear. After $3162 \mathrm{~min}$ of ageing, one of the ferrite phase peaks decreases to nearly zero but the other peak does not disappear; it overlaps with a sigma phase peak. After longer periods of time such as $10000 \mathrm{~min}$, the treatments promote the transformation of ferrite phase. This results in a noticeable decrease in the intensity of the $\alpha$ and an increase of $\gamma$ peaks. The decrease of the ferrite peak intensity indicates that the major fraction of ferrite is transformed into sigma. Consequently several sigma peaks are observed. All the changes observed in the diffraction peak intensity do correlate well with the changes in volume fraction of each phase during the isothermal hold as given in Table 2. 
TABLE 4: EDS analysis of phases present in solution-annealed and aged condition of DSS.

\begin{tabular}{|c|c|c|c|c|c|c|c|c|}
\hline Heat treatment & Phase & $\mathrm{Cr}($ wt. \%) & $\mathrm{Ni}($ wt. \%) & Mo (wt. \%) & Mn (wt. \%) & Si (wt. \%) & S (wt. \%) & $\mathrm{Fe}$ (wt. \%) \\
\hline Solutionannealed & General composition & 22.04 & 4.45 & 2.69 & 1.49 & 0.45 & 0.003 & 68.29 \\
\hline \multirow{2}{*}{ Solution annealed } & $\alpha$ & 26.32 & 4.87 & 4.15 & 1.59 & 0.74 & - & 62.32 \\
\hline & $\gamma$ & 23.55 & 7.08 & - & 1.85 & - & 1.19 & 66.33 \\
\hline \multirow{4}{*}{$725^{\circ} \mathrm{C} / 31622 \mathrm{~min}$} & $\gamma$ & 23.81 & 6.43 & - & - & - & - & 69.76 \\
\hline & $\sigma$ & 35.21 & - & 7.21 & - & - & - & 57.58 \\
\hline & $\gamma_{2}$ & 23.03 & 6.91 & - & - & 1.04 & 1.26 & 67.75 \\
\hline & $\gamma_{2}$ & 18.65 & 5.21 & & & & & 76.14 \\
\hline
\end{tabular}

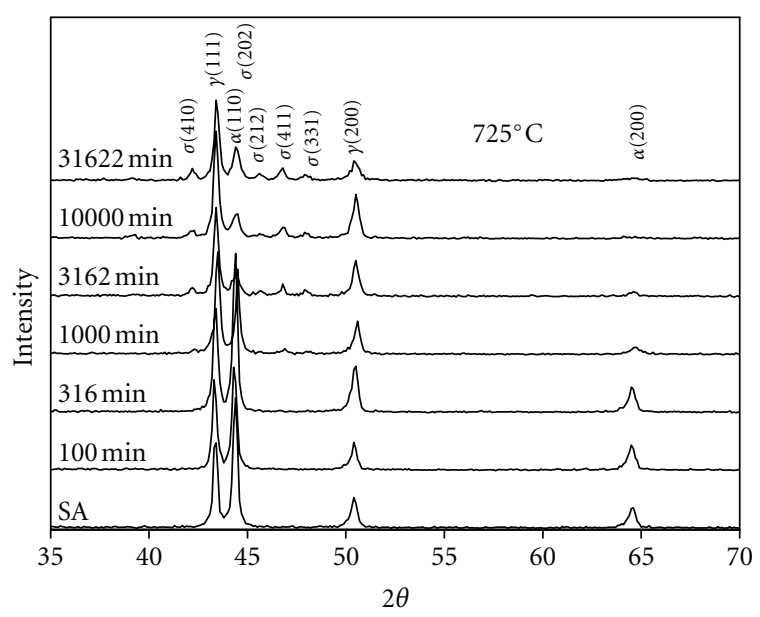

FIgURE 6: X-Ray diffraction patterns of samples aged at $725^{\circ} \mathrm{C}$.

3.6. DLEPR Results. Figure 7 shows the polarization curves for samples in solution-annealed and aged condition. The curve obtained from the solution-annealed sample is treated as a reference and compared with the others. The activation peak current density of the reference curve is $23.13 \mathrm{~mA} / \mathrm{cm}^{2}$, and the corresponding activation peak potential $\left(E_{a}\right)$ or passivation potential $\left(E_{\text {pass }}\right)$ is $-212.78 \mathrm{mV}$ with respect to saturated calomel reference electrode (SCE). This peak reaches a maximum and then fall, to a low passive current density $\left(I_{\text {pass }}\right)$ of $0.001448 \mathrm{~mA} / \mathrm{cm}^{2}$ before reaching the chosen reverse potential of $+250 \mathrm{mV}$. The sample is thus passivated in a wide range between $-212.78 \mathrm{mV}$ and $+250 \mathrm{mV}$. In this passive range, a thin invisible film of oxide may cover the metal surface. The protective film acts as a barrier between the metal and its environment and reduces its rate of dissolution. And hence, the $I_{r} / I_{a}$ ratio is very low $(0.027634 \%)$. This may be considered as unsensitized material (Table 5).

From the samples aged for $100 \mathrm{~min}$, any visible precipitate is not observed either optically (Figure 2(a)), or in XRD analysis (Figure 6). After ageing for $316 \mathrm{~min}$, sigma phase nucleation starts at $\alpha / \gamma$ phase boundaries as shown in Figure 2(b), but the diffraction pattern (Figure 6) does not reveal any evidence due to very small amount of the sigma phase (0.6\%), (Table 2). The samples aged for 100 and $316 \mathrm{~min}$ present very small reactivation currents (Table 5), and hence the $I_{r} / I_{a}$ ratios are 5.76 and $6.48 \%$, and accordingly the corrosion rates become 0.49451 and $2.37328 \mathrm{mdd}$, respectively. This means slight chromium depletion resulting in a less sensitization.

After $1000 \mathrm{~min}$, the $\sigma$ precipitates have grown at the boundaries and within the ferrite grains. Next to the growing $\sigma$-phase, the secondary austenite $\left(\gamma_{2}\right)$ forms from the decomposition of ferrite into $\sigma$ and $\gamma_{2}$ (Table 2). Dissolution of the secondary austenite results in greater weight loss (5.38 mdd) (Table 3) and accordingly a high ratio of $I_{r} / I_{a}$ (53.42\%) (Table 5). This means that the sample has been highly sensitized.

After 3162 min of ageing, a substantial decrease in chromium content of the interfaces and around the precipitates reduces the corrosion resistance and makes the alloy more susceptible to localized attacks. This leads to the highest grade of sensitization, and thus the DOS value reaches $93.189 \%$ (Table 5), and dissolution of the secondary austenite $\left(\gamma_{2}\right)$ results in a corrosion rate of $5.161 \mathrm{mdd}$ (Table 3).

Similar results were obtained for the same reasons after ageing for 10000 and $31622 \mathrm{~min}$. The corresponding DOS are 90.4 and $92.39 \%$, and the mdd values are 5.28 and 6.04 respectively, showing the samples being heavily sensitized (see Table 5 for comparison).

When the polarization curves of the samples aged at $725^{\circ} \mathrm{C}$ from 100 to $31622 \mathrm{~min}$ are compared with the reference curve, it is seen that the activation peak current density increases with increasing ageing times (Table 5). And also the passive current density increases from $0.033688 \mathrm{~mA} / \mathrm{cm}^{2}$ up to $0.059391 \mathrm{~mA} / \mathrm{cm}^{2}$, and the passivation potential $\left(E_{\text {pass }}\right)$ decreases from $-212.78 \mathrm{mV}$ to $-172.23 \mathrm{mV}$.

From the results discussed so far considering weight loss acid test and DLEPR test, it can be concluded that both the sensitization and the corrosion rate have increased with respect to the depletion of chromium and molybdenum in the ferrite region.

Chromium diffusion is much faster in ferrite than in austenite. The chromium concentrates in the neighboring sigma phase [21] and causes the sigma phase to grow fast within the ferrite region. As a result, the formation of the secondary austenite can degrade the stability of the passive film [22].

After the DLEPR test, a sample aged for 31622 min was slightly polished and examined with LOM (Figure $8(\mathrm{a})$ ) to check the attack locations and the relationship with the chromium-depleted areas.

Observation of the surface indicates that the sigma and austenite phases are almost intact, while the secondary 


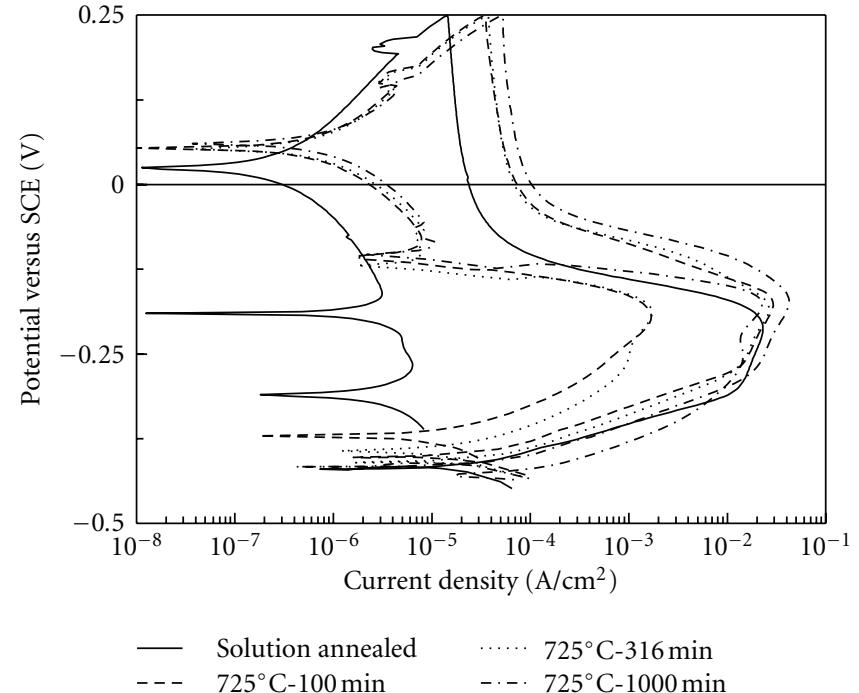

(a)

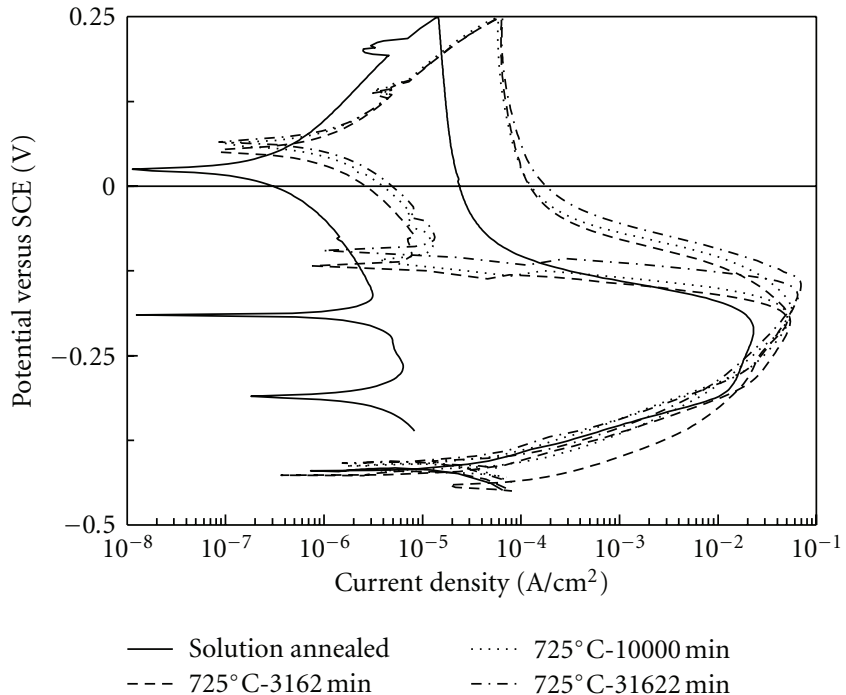

(b)

FIGURE 7: DLEPR curves plotted for DSS after solution and sensitization heat treatments at $725^{\circ} \mathrm{C}$ between 100 and 31622 min (scan rate: $15 \mathrm{~V} / \mathrm{hr})$.

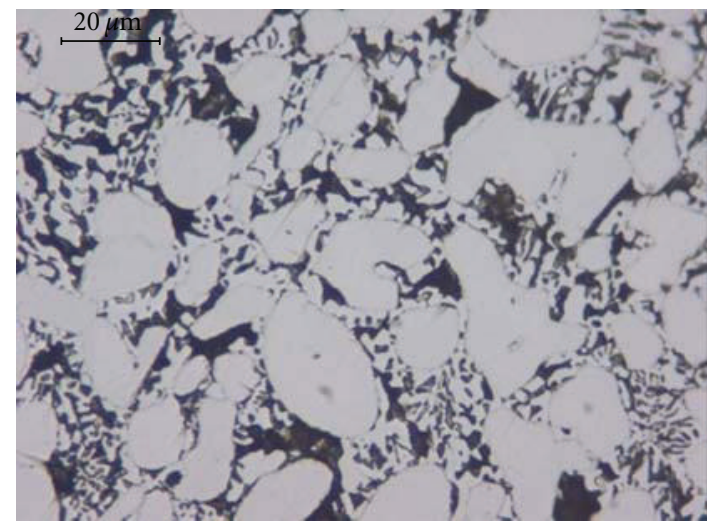

(a)

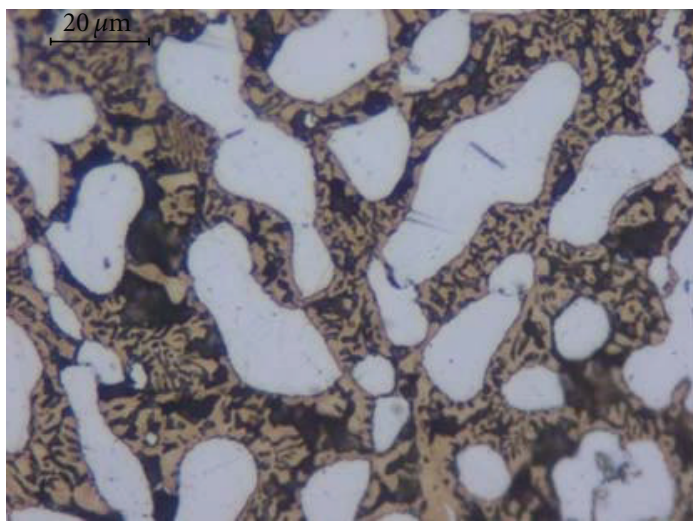

(b)

Figure 8: Optical micrographs after DLEPR test for sample aged at $725^{\circ} \mathrm{C}$ for $31622 \mathrm{~min}$ (a) after slightly polished (large austenite in white, attacked regions in black, sigma: small white regions) (b) electrolytically etched with $\mathrm{NaOH}$ (austenite in white, sigma in brown, attacked regions in black).

TABLE 5: DLEPR Test results of 2205 type duplex stainless steel.

\begin{tabular}{lcccccc}
\hline Temperature $\left({ }^{\circ} \mathrm{C}\right)$ & $\begin{array}{c}\text { Time } \\
(\mathrm{min})\end{array}$ & $\begin{array}{c}\text { Activation peak } \\
\text { potential, } E_{a}(\mathrm{mV})\end{array}$ & $\begin{array}{c}\text { Activation peak } \\
\text { current density, } \\
I_{a}\left(\mathrm{~mA} / \mathrm{cm}^{2}\right)\end{array}$ & $\begin{array}{c}\text { Reactivation peak } \\
\text { potential, } E_{r}(\mathrm{mV})\end{array}$ & $\begin{array}{c}\text { Reactivation peak } \\
\text { current density, } \\
I_{r}\left(\mathrm{~mA} / \mathrm{cm}^{2}\right)\end{array}$ & $\begin{array}{c}\text { Passivation } \\
\text { current density, } \\
I_{\text {pass }}\left(\mathrm{mA} / \mathrm{cm}^{2}\right)\end{array}$ \\
$\begin{array}{l}\text { Solution annealed } \\
\text { at } 1050^{\circ} \mathrm{C}, 1 \mathrm{hr}\end{array}$ & -212.78 & 23.1304849 & -267.33 & 0.0063918 & 0.001448 \\
\hline & 100 & -178.33 & 29.2261754 & -196.13 & 1.6857088 & 0.033688 \\
$\left(I_{r} / I_{a} \times 100\right)$
\end{tabular}


austenite and some iron rich ferrite phase are attacked. The corroded secondary austenite regions appear in black, and the isolated sigma precipitates in white. Large primary austenite grains remain in white as usual. To distinguish sigma and primary austenite phases in color, the samples were electrolytically etched with $\mathrm{NaOH}$ reagent. The sigma phase is colored reddish brown and distinguished from the primary austenite which was not affected from the etchant (Figure 8(b)).

When compared to the acid test samples (Figure 5), the DLEPR specimens showed a similar behavior, because the same areas were affected in both cases. In other words the attacks have occurred at sensitized areas. The appearance of the localized attack after immersion testing shows large number of black points clearly. This shows that local corrosion is initiated in the secondary austenite phase as happened in the DLEPR test samples. Once a pit is formed, it rapidly propagates within the initial ferrite region. After a long time of exposure, the corroded area extended and covered a large area including many sigma and austenite phases. As a result large cavities were developed. This type of corrosion is known as localized corrosion.

As mentioned before, Arikan and Doruk presented a study [12] dealing with DLEPR and standard weight loss acid tests for the same type of duplex stainless steel annealed at $1050^{\circ} \mathrm{C}$ for 1 hour and aged at $650^{\circ} \mathrm{C}$ for various periods of time.

Comparison of the results obtained from samples aged at 650 and $725^{\circ} \mathrm{C}$ indicates that the minimum time where sigma was first observed is less than $316 \mathrm{~min}$ at $725^{\circ} \mathrm{C}$ and longer as $1000 \mathrm{~min}$ at $650^{\circ} \mathrm{C}$. Both DLEPR and acid tests expose continuous chromium-depleted zones leading to intergranular corrosion at $\alpha / \gamma$ phase boundaries and local corrosion around sigma phases precipitated inside the ferrite region.

Corrosion rate of samples aged at $650^{\circ} \mathrm{C}$ is very low up to $1000 \mathrm{~min}$ and then increases up to $31622 \mathrm{~min}$, whereas the rate for samples aged at $725^{\circ} \mathrm{C}$ is very low only for $100 \mathrm{~min}$ of ageing and then rapidly increases with ageing time (Table 3 ).

A similar trend for DOS values was observed at 650 and $725^{\circ} \mathrm{C}$, but since ferrite decomposition occurs faster at $725^{\circ} \mathrm{C}$, accordingly sensitization begins in shorter time of ageing than that at $650^{\circ} \mathrm{C}$. This indicates that The DLEPR test provides results proportional to $\sigma$-phase content.

As a result, in both cases, the sensitization and corrosion rate depend strongly on the extent of chromium and molybdenum depletion. The important difference is the depletion to be delayed at $650^{\circ} \mathrm{C}$.

Only the solution-annealed samples and the samples aged at $650^{\circ} \mathrm{C}$ for 100 and $316 \mathrm{~min}$ are unsensitized but samples aged at $650^{\circ} \mathrm{C}$ for 10000 and $31622 \mathrm{~min}$ are heavily sensitized. Similarly, samples after $1000 \mathrm{~min}$ of ageing at $725^{\circ} \mathrm{C}$ are sensitized as well.

3.7. Analysis of Polarization Curves in Reverse Scanning. At the beginning of the reverse scanning, the anodic current density decreases, and the anodic curve moves to the left (Figure 7). This is an indication of thickening of the oxide film. On decreasing the potential, the anodic current density

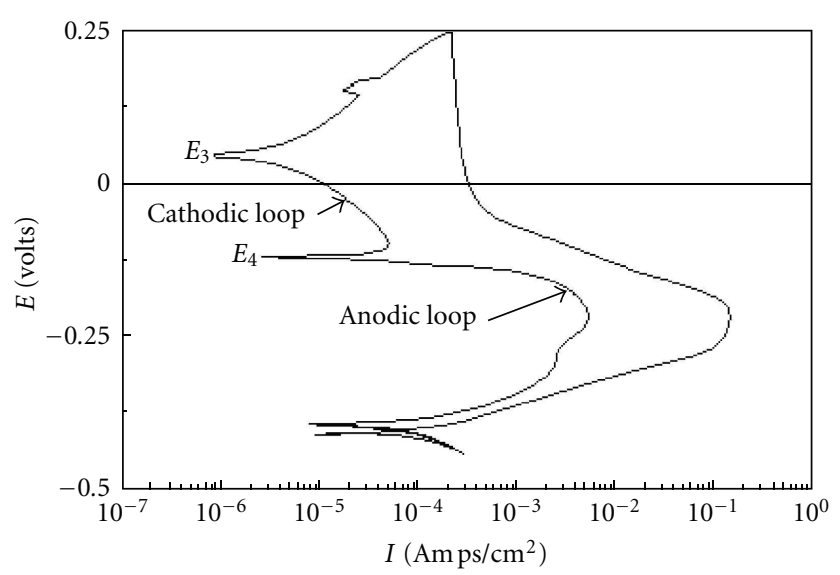

FIgURE 9: Cathodic and anodic loops in DLEPR curve.

is reduced nearly to zero. This is due to the slowing of the anodic dissolution kinetics caused by thickening of the passive film. The sample has thus continued to passivate from $E_{\text {pass }}$ through $E_{\text {rev }}$, back to potential $E_{3}$. Further reducing the potential, the direction of the current density has changed between $E_{3}$ and $E_{4}$ as shown in Figure 9. It shows a loop consisting of cathodic current [23]. The origin of the cathodic current can be attributed to the fact that at potentials between $E_{3}$ and $E_{4}$, the rate of the cathodic reaction is greater than the anodic current density, and hence the net current is cathodic over the potential range, $\Delta E\left(=E_{3}-E_{4}\right)$ (Table 6). If the potential is further reduced on the reverse scan, the direction of the current density changes back, and an anodic reactivation loop is generated. This indicates that the oxide has dissolved, and metal dissolution reaction has occurred. The development of the reactivation peak current density $\left(I_{r}\right)$ can be attributed to metal dissolution. The lowered reactivation peak current density $I_{r}$ (on the reverse scan) is due to incomplete reactivation of the metal surface.

If no cathodic loop was generated on the reverse scan, the anodic reactivation would begin at a higher potential and would likely reach a high value of $I_{r}$ in a short time, and thus the metal dissolution would take place.

The same cathodic loop behavior is observed on the reverse scans of polarization curves obtained from the solution annealed and aged samples by DLEPR test (Table 6).

The potential ranges $(\Delta E)$ of samples aged at $725^{\circ} \mathrm{C}$ from 100 and $31622 \mathrm{~min}$ where the cathodic loops are obtained, are different from that of the solution-annealed sample. In general, their reactivation curves look like that of the solution-annealed sample. A similar cathodic loop behavior has been observed for all cases but the anodic loops do not resemble that of the solution-annealed sample. This indicates that the precipitates developed in the microstructure influence the polarization behavior.

For all cases, the potential ranges $(\Delta E)$ for the cathodic loops change disorderly from 0.159 to 0.171 and are less than that of the solution-annealed sample. This means that the formation of the cathodic loop delays the occurrence of the anodic reactivation current loop for a short time. Then, the direction of the current density changes back quickly, and 
TABLE 6: DLEPR test results on the reverse scans of polarization curves.

\begin{tabular}{lcccccc}
\hline Temperature $\left({ }^{\circ} \mathrm{C}\right)$ & Time $(\mathrm{min})$ & $E_{3}($ volt $)$ & $E_{4}($ volt $)$ & $\Delta E\left(=E_{3}-E_{4}\right)($ volt $)$ & $I_{r}\left(\mathrm{~mA} / \mathrm{cm}^{2}\right)$ & $\mathrm{DOS}\left(I_{r} / I_{a} \times 100\right)$ \\
\hline $\begin{array}{l}\text { Solution annealed at } \\
1050^{\circ} \mathrm{C}, 1 \mathrm{hr}\end{array}$ & & 0.02521 & -0.190090 & 0,215300 & 0.0063918 & 0.027634 \\
\hline & $\mathbf{1 0 0}$ & 0.053818 & -0.110000 & 0.163818 & 1.6857088 & 5.767805 \\
& $\mathbf{3 1 6}$ & 0.052163 & -0.119650 & 0.171813 & 1.7231466 & 6.484404 \\
Solution annealed at & $\mathbf{1 0 0 0}$ & 0.060101 & -0.103310 & 0.163411 & 22.5825614 & 53.421053 \\
$1050^{\circ} \mathrm{C}, 1 \mathrm{hr}+$ aged at & $\mathbf{3 1 6 2}$ & 0.050114 & -0.117800 & 0.167914 & 50.5214698 & 93.189389 \\
$725^{\circ} \mathrm{C}$ & $\mathbf{1 0 0 0 0}$ & 0.063035 & -0.108430 & 0,171465 & 50.4425582 & 90.422059 \\
& $\mathbf{3 1 6 2 2}$ & 0.064701 & -0.095247 & 0.159948 & 64.3463484 & 92.394528 \\
\hline
\end{tabular}

the anodic reactivation current density begins to be generated at a potential of $E_{4}=-0.110000 \mathrm{~V}$ for ageing $100 \mathrm{~min}$ and at $E_{4}=-0.119650 \mathrm{~V}$ for ageing $316 \mathrm{~min}$. It then reaches the peak value of $I_{r}=1.6857088 \mathrm{~A} / \mathrm{cm}^{2}$ with the DOS value of $5.76 \%$ for ageing $100 \mathrm{~min}$, and $I_{r}=1.7231466 \mathrm{~A} / \mathrm{cm}^{2}$ with the DOS value $6.48 \%$ for ageing 316 minutes.

For the sample aged for $1000 \mathrm{~min}$, the potential range for the cathodic loop is $0.163411 \mathrm{~V}$. This is lower than the value measured for the solution-annealed one. The dissolution of oxide begins at a high potential such as $E_{4}=-0.103310 \mathrm{~V}$. After a short delay, the reactivation current density increases to $I_{r}=22.5825614 \mathrm{~A} / \mathrm{cm}^{2}$. The DOS value is $53.42 \%$.

For the sample aged for $3162 \mathrm{~min}$, the range of the potential for the cathodic loop is $0.167914 \mathrm{~V}$. This is higher than the value obtained for $1000 \mathrm{~min}$ of ageing. The $E_{4}$ (= $-0.117800 \mathrm{~V})$ has been found higher and $E_{3}(=0.050114)$ lower with increasing ageing time. The reactivation peak current density $\left(I_{r}\right)$ has reached $50.52146 \mathrm{~mA} / \mathrm{cm}^{2}$ corresponding to a high DOS value (93.18\%).

For ageing time of 10000 and $31622 \mathrm{~min}$, cathodic loops on the reverse scan are obtained within a potential range of 0.171465 and $0.159948 \mathrm{~V}$, respectively. And then the anodic reactivation loops suddenly begin at higher potentials of $E_{4}$ such as -0.108430 and $-0.095247 \mathrm{~V}$. The reactivation peak current densities $\left(I_{r}\right)$ have reached to 50.442 and $64.346 \mathrm{~mA} / \mathrm{cm}^{2}$, and the corresponding DOS values are 90.422 and $92.394 \%$, respectively. This is because of the change in the microstructure. Due to longer ageing treatments the whole ferrite has transformed into $\sigma$ and $\gamma_{2}$. Dissolution of the secondary austenite results in greater weight losses and higher ratios of $I_{r} / I_{a}$. The higher anodic peak reactivation current density is the result of complete activation of the metal surface as evident by the high DOS values.

A similar behavior has been observed for the passive current densities $\left(I_{\text {pass }}\right)$. The chromium depletion or dissolution of secondary austenite phase $\left(\gamma_{2}\right)$ causes the passive current densities to shift to higher current densities as compared to that obtained from the solution-annealed sample (Figure 7, Table 5).

\section{Conclusions}

The effect of isothermal treatment at $725^{\circ} \mathrm{C}$ on the microstructures and consequent corrosion behavior of a duplex stainless steel UNS S31803 was investigated. The important findings are summarized as follows.

(a) Only the solution-annealed sample was found unsensitized. The structure is free of precipitations, and consequently it presented a very small reactivation current. From the DOS values of specimens aged for 100 and $316 \mathrm{~min}$., it may be concluded that these samples became less sensitized than those aged for longer ageing time. The degree of sensitization increases rapidly with increasing ageing time and this can be attributed to a higher contribution of chromium- and molybdenum-depleted areas resulting in the formation of the intermetallic phases.

(b) In a comparison to previous results [12], the sensitization of DSS was affected much by long-term ageing heat treatment at $725^{\circ} \mathrm{C}$ than that at $625^{\circ} \mathrm{C}$.

(c) The DLEPR test showed that fine precipitates were insufficient to induce a significant susceptibility to intergranular corrosion. The role of chromium nitrides was less harmful because of the low amount of these precipitates.

(d) The intermetallic $\sigma$-phase has first precipitated at the interface of $\alpha / \gamma, \alpha / \alpha$, and inside the $\alpha$-ferrite grains up to $316 \mathrm{~min}$ ageing time. The $\sigma$-phase has then grown into coarse particles due to high diffusivity of chromium and molybdenum atoms in the ferrite matrix leaving behind a chromium-depleted zone named secondary austenite. The exposure of aged samples to iron-chloride acid media leads to a localized and selective attack on the secondary austenite.

(e) From the observations of the polarization curves it may also be concluded that cathodic loops do not affect metal dissolution. They merely delay the occurrence of anodic loops for a short time in a small potential range. These potential ranges $(\Delta E)$ over that cathodic loops are obtained depend on the protective film thickness, ageing temperature, time, and microstructural changes in the material. Actually, during the anodic sweep, the entire surface is active and contributes to the peak current. But during the reactivation sweep, only the sensitized areas contribute to the passiveactive transition. So the oxide dissolves first, and then soon metal dissolution takes place.

\section{References}

[1] A. Wensley and C. Reid, "Duplex stainless steels in the pulp and paper industry," in Proceedings of the Duplex Stainless Steels, J. Charles and S. Bernhardsson, Eds., vol. 1, pp. 10991110, Les Editions de Physique, 1992. 
[2] J. Husbands and P. K. Whitkraft, "High-Cr Duplex Alloy in Nitric Acid Production," CORROSION/91, Paper 171, NACE, Houston, Tex, USA, 1991.

[3] D. J. A. Fruytier, "Industrial experiences with duplex stainless steel related to thier specific properties," in Proceedings of the Duplex Stainless Steels, J. Charles and S. Bernhardsson, Eds., pp. 497-509, Les Editions de Physique, 1992.

[4] P. Jolly, Bulletin du Cercle d'Etudes des Metaux, vol. 12, no. 5, p. $317,1973$.

[5] J. S. Kim and H. S. Kwon, "Effects of tungsten on corrosion and kinetics of sigma phase formation of $25 \%$ chromium duplex stainless steels," Corrosion, vol. 55, no. 5, pp. 512-521, 1999.

[6] M. E. Wilms, V. J. Gadgil, J. M. Krougman, and B. H. Kolster, "Effect of $\sigma$-phase precipitation at $800^{\circ} \mathrm{C}$ on the mechanical properties of a high alloyed duplex stainless steel," Materials at High Temperatures, vol. 9, no. 3, pp. 160-166, 1991.

[7] T. H. Chen and J. R. Yang, "Effects of solution treatment and continuous cooling on $\sigma$-phase precipitation in a 2205 duplex stainless steel," Materials Science \& Engineering A., vol. 311, no. $1-2$, pp. 28-40, 2001

[8] T. A. Debold, "Duplex stainless steel-microstructure and properties," Journal of Metals, vol. 41, no. 3, pp. 12-15, 1989.

[9] N. Lopez, M. Cid, and M. Puiggali, "Influence of $\sigma$-phase on mechanical properties and corrosion resistance of duplex stainless steels," Corrosion Science, vol. 41, no. 8, pp. 1615$1631,1999$.

[10] ASTM A262-02: Standard Practices for Detecting Susceptibility to Intergranular Attack in Austenitic Stainless Steels.

[11] ASTM G108-94: Standard Test Method for Electrochemical Reactivation (EPR) for Detecting Sensitizatipn of AISI Type 304 and 304 L Stainless Steels.

[12] M. E. Arikan and M. Doruk, "Determination of susceptibility to intergranular corrosion of UNS 31803 type duplex stainless steel by electrochemical reactivation method," Turkish Journal of Engineering and Environmental Sciences, vol. 32, no. 6, pp. 323-335, 2008.

[13] ASTM A923-03: Standard Test Methods for Detecting Detrimental Intermetallic Phase in Duplex Austenitic/Ferritic Stainless Steels.

[14] A. P. Majidi and M. A. Streicher, "Potentiodynamic reactivation method for detecting densitization in AlSl 304 and 304L stainless steels," Corrosion, vol. 40, no. 8, pp. 393-408, 1984.

[15] A. P. Majidi and M. A. Streicher, paper presented at NACE, CORROSION/84, no. 261, 1984.

[16] P. Jolly and J. Hochmann, Mémoires Scientifiques de la Revue de Metallurgie, vol. 20, p. 117, 1993.

[17] J. M. Vitek and S. A. David, "The sigma phase transformation in austenitic stainless steels," Welding Journal, vol. 63, no. 4, pp. 106-111, 1986.

[18] "Duplex stainless steel: a tale of two phases," in Proceedings of the Duplex Stainless Steels, H. D. Solomon, T. M. Devine, and R. A. Lula, Eds., p. 693, ASM, Metals Park, Ohio, USA, 1986.

[19] C. H. Shek, K. W. Wong, and J. K. Lai, "Review of temperature indicators and the use of duplex stainless steels for life assessments," Materials Science and Engineering, vol. 5-6, p. 153, 1997.

[20] T. A. Debold, "Duplex stainless steel-microstructure and properties," Journal of Metals, vol. 41, no. 3, pp. 12-15, 1989.

[21] R. N. Wright and R. A. Rula, "Toughness of ferritic stainless steels," ASTM International, vol. 706, p. 2, 1979.

[22] C. J. Park and H. S. Kwon, "Effects of aging at $475^{\circ} \mathrm{C}$ on corrosion properties of tungsten-containing duplex stainless steels," Corrosion Science, vol. 44, no. 12, pp. 2817-2830, 2002.
[23] A. Legat and V. Dolecek, "Chaotic analysis of electrochemical noise measured on stainless steel," Journal of the Electrochemical Society, vol. 142, no. 6, pp. 1851-1858, 1995. 

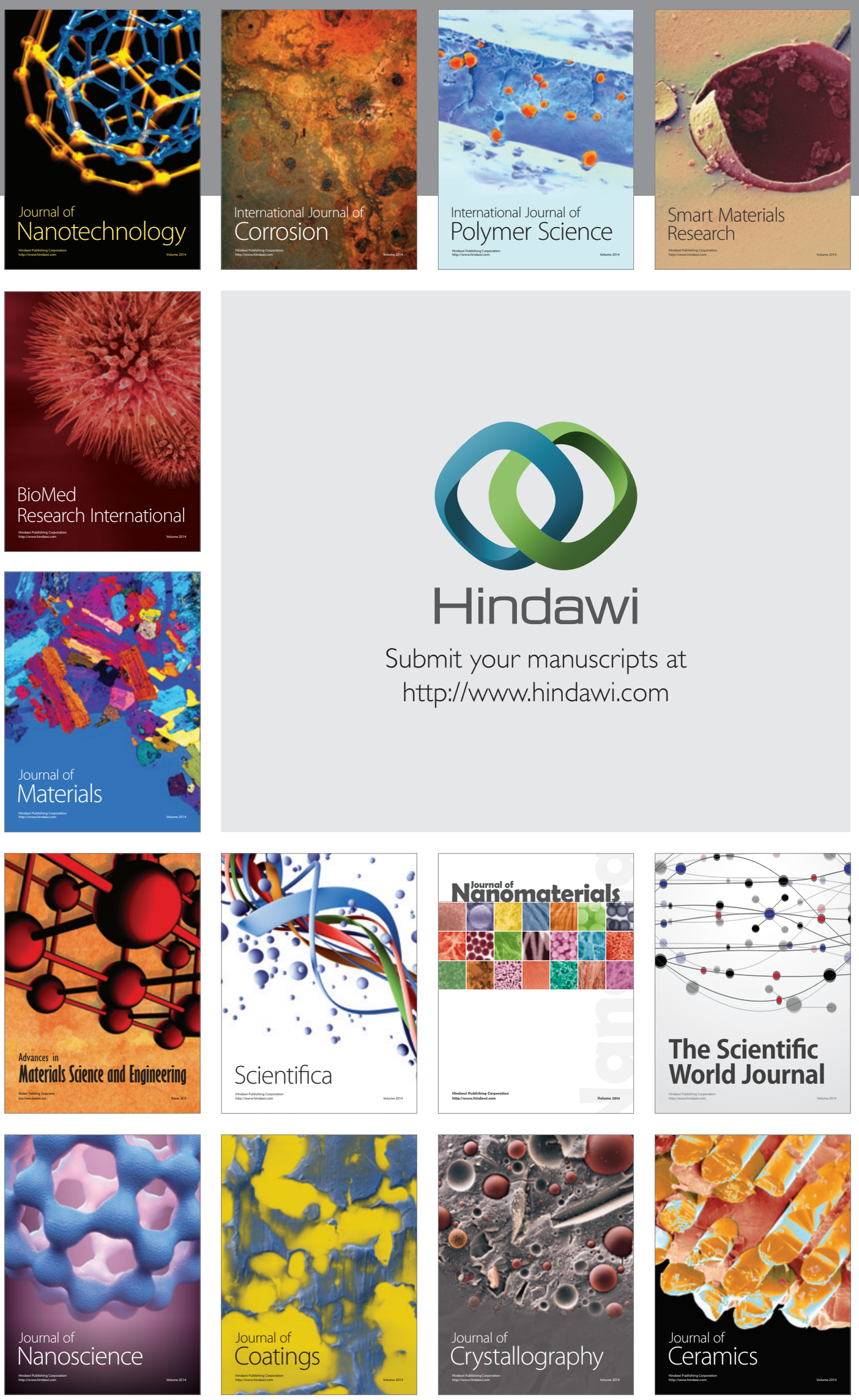

The Scientific World Journal

Submit your manuscripts at

http://www.hindawi.com

\section{World Journal}

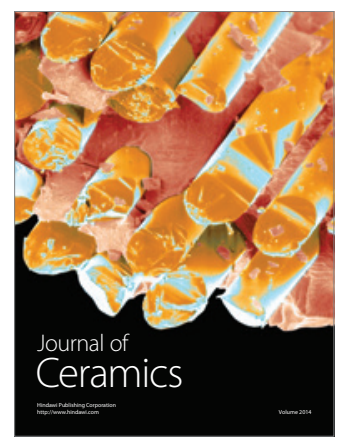

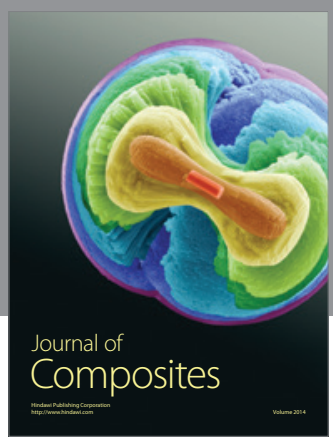
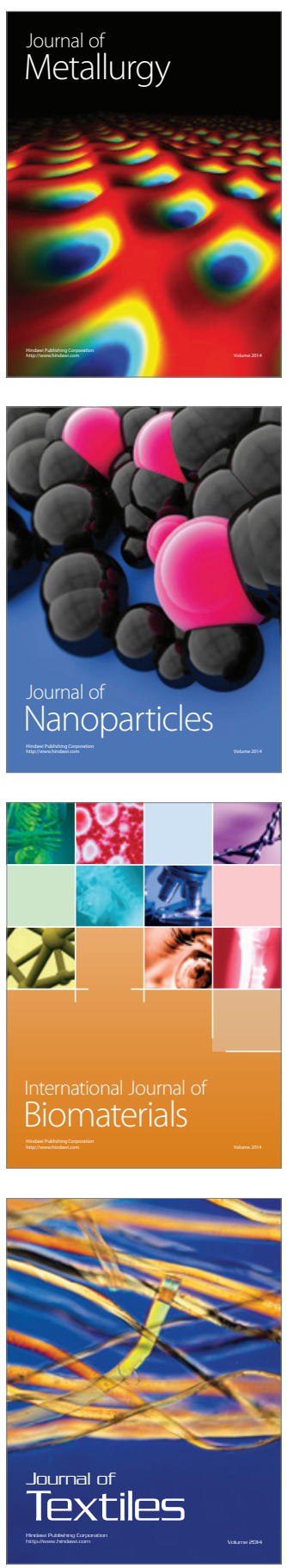